\title{
Dynamic competition with consumer inertia
}

\author{
Citation for published version (APA):
}

Pot, E. A., Flesch, J., Peeters, R. J. A. P., \& Vermeulen, A. J. (2011). Dynamic competition with consumer inertia. METEOR, Maastricht University School of Business and Economics. METEOR Research Memorandum No. 016 https://doi.org/10.26481/umamet.2011016

\section{Document status and date:}

Published: 01/01/2011

DOI:

10.26481/umamet.2011016

Document Version:

Publisher's PDF, also known as Version of record

\section{Please check the document version of this publication:}

- A submitted manuscript is the version of the article upon submission and before peer-review. There can be important differences between the submitted version and the official published version of record.

People interested in the research are advised to contact the author for the final version of the publication, or visit the DOI to the publisher's website.

- The final author version and the galley proof are versions of the publication after peer review.

- The final published version features the final layout of the paper including the volume, issue and page numbers.

Link to publication

\footnotetext{
General rights rights.

- You may freely distribute the URL identifying the publication in the public portal. please follow below link for the End User Agreement:

www.umlib.nl/taverne-license

Take down policy

If you believe that this document breaches copyright please contact us at:

repository@maastrichtuniversity.nl

providing details and we will investigate your claim.
}

Copyright and moral rights for the publications made accessible in the public portal are retained by the authors and/or other copyright owners and it is a condition of accessing publications that users recognise and abide by the legal requirements associated with these

- Users may download and print one copy of any publication from the public portal for the purpose of private study or research.

- You may not further distribute the material or use it for any profit-making activity or commercial gain

If the publication is distributed under the terms of Article $25 \mathrm{fa}$ of the Dutch Copyright Act, indicated by the "Taverne" license above, 


\section{Maastricht University}

Erik Pot, János Flesch, Ronald Peeters, Dries Vermeulen

\section{Dynamic Competition with Consumer I nertia}

$\mathrm{RM} / 11 / 016$

(RM/09/037 - revised-)

\section{METEOR}

Maastricht University School of Business and Economics

Maastricht Research School of Economics

of Technology and Organization

P.O. Box 616

NL - 6200 MD Maastricht

The Netherlands 


\title{
Dynamic Competition with Consumer Inertia*
}

\author{
Erik $\operatorname{Pot}^{\dagger} \quad J_{\text {János Flesch }}^{\dagger} \quad$ Ronald Peeters ${ }^{\dagger} \quad$ Dries Vermeulen $^{\dagger}$
}

February 23, 2011

\begin{abstract}
We study a framework where two duopolists compete repeatedly in prices and where chosen prices potentially affect future market shares, but certainly do not affect current sales. This assumption of consumer inertia causes (noncooperative) coordination on high prices only to be possible as an equilibrium for low values of the discount factor. In particular, high discount factors increase opportunism and aggressiveness of competition to such an extent that high prices are no longer sustainable as an equilibrium outcome (not even in trigger strategies). In addition, we find that both monopolization and enduring market share and price fluctuations (price wars) can be equilibrium path phenomena without requiring exogenous shocks in market or firm characteristics.
\end{abstract}

Keywords: Dynamic duopolistic competition; Consumer inertia; Endogenous market shares; Monopolization.

JEL Classification Numbers: C73; D43; L13.

\section{Introduction}

An important goal of research on price competition in oligopolistic markets is to determine which circumstances are associated with high prices and which ones with low prices. ${ }^{1}$ Often these two modes of pricing behavior are connected; for instance, when firms revert to low prices for a fixed or unlimited period in response to a deviation from a coordinated (possibly via a collusive agreement) high price (Friedman, 1971). Such trigger strategies are known to sustain high prices when firms are sufficiently future-oriented (i.e. the discount factor is sufficiently high). Moreover, firm and market characteristics should be sufficiently stable, since periods of low prices (or, price war behavior) can occur on the equilibrium path when exogenous shocks

\footnotetext{
${ }^{*}$ The content of this paper has been presented at MLSE (Maastricht, 2009), SEDesign (Maastricht, 2009), SEDynamics (Istanbul, 2009), SAET (Ischia, 2009), EARIE (Ljubljana, 2009), Game Theory Seminar (Tilburg, 2010) and SING (Palermo, 2010) and we thank the respective audiences for their helpful comments and suggestions. R. Peeters would like to thank the Netherlands Organisation for Scientific Research (NWO) for financial support.

${ }^{\dagger}$ Maastricht University, P.O. Box 616, 6200 MD Maastricht, The Netherlands. Email address corresponding author: r.peeters@maastrichtuniversity.nl

${ }^{1}$ Excessive pricing may result from collusive agreements, but might as well arise naturally as a consequence of situational characteristics (Porter and Zona, 1999).
} 
in market demand (Rotemberg and Saloner, 1986), individual demand (Pot et al., 2008), or individual marginal cost level (Athey et al., 2004) are possible. A common design property of the models that predict high prices for high discount factors is the particular time-tradeoff, where a price undercut leads to an immediate demand and profit increase, but to a decrease in future profits due to reversion to profit eroding marginal cost pricing in response to the undercut.

However, a price decrease may not always lead to an immediate increase in demand that suffices to increase immediate profit, although it may induce increased clientele and profit opportunities in the future. Reasons for this include presence of brand loyalty, switching costs, or demand inertia (cf. Fishman and Rob, 2003). When the market is characterized by this property, firms are constantly exposed to a reverted time-tradeoff. Each period, firms have on the one hand the incentive to exploit currently installed market share by setting a high price (harvesting incentive), and on the other hand the incentive to set a low price thereby foregoing immediate profit opportunities in exchange for an increased future market share (investment incentive). ${ }^{2}$ There are two prominent motives for low pricing: a firm may price low in an attempt to increase market share (offensive motive), but could as well price low to avoid loss of market share (defensive motive). These incentives and motives are important and recurrent aspects in our study.

Our model contains two duopolists that compete over a discrete infinite time horizon under possibly varying states of the market. The states are represented by a finite number of possible market shares divisions, including two monopolistic states. At each period, given a competitive state where both firms have a positive market share, firms have the option to either charge a high price or a low price. Since we assume sales in a particular period to equal the market share in that particular period, the high price renders a higher immediate profit. But, by charging the high price a firm runs the risk of losing part of its market share in the subsequent period in case the opponent opts for a low price. Hence, our model explicitly assumes consumers to be inert. We allow for monopolization and bankruptcy by assuming that the two monopolistic states are absorbing. Our model falls within the class of finite discounted stochastic games and we adopt known methods and techniques from that literature in our equilibrium analysis. In doing so, we restrict our attention to (symmetric pure) stationary subgame-perfect equilibria. This provides us with the following results and insights.

For sufficiently low discount factors the harvesting incentive dominates the investment incentive which results in the unique equilibrium prediction of firms charging high prices. When the discount factor is sufficiently large this dominance relation among incentives reverts and

\footnotetext{
${ }^{2}$ Farrell and Klemperer (2007) provides a detailed overview of different incentives and effects that appear in oligopolistic markets.
} 
firms will opt for the low price. The outcomes with high prices and low prices uniformly over states typically do not co-exist as a stationary subgame-perfect equilibrium. Surprisingly, coordination on high prices can no longer be supported as stationary subgame-perfect equilibrium. This may even be true when we allow for trigger strategies.

This result contrasts starkly with that found in the standard literature on dynamic price competition, where high discount factors induce sustainability of high prices. Those models typically have the low price outcome as the unique equilibrium prediction of the state game, whereas in our model it is the high price outcome. So, where a high discount factor facilitates high prices in those models, it knocks it down in our model. Hence, after augmenting the standard model with a realistic market characteristic we obtain precisely the opposite expectations on firm behavior and market performance.

Finally, our model is able to give an explanation for monopolization and enduring market share and price fluctuations (price wars) as an equilibrium path phenomenon without the presence of exogenous shocks in market or firm characteristics. Equilibria that induce one of these interesting price dynamics only exist for intermediate values of the discount factors. When the discount factor is too low, firms have no incentive to incur costs today in exchange for future market share, while simultaneously firms do not fear a loss of market share due to the similar lack of offensive motives of the opponent. Hence, both firms exploit their customer base by demanding high prices. When the discount factor is too high, firms resort to aggressive pricing in all states. Incentives to increase market share (or even to monopolize the market) are high and so is the fear for loss of market share.

A noteworthy paper in the light of our findings is Chen and Rosenthal (1996), in which it is also noted that the predicted outcome of traditional Bertrand competition is affected in a crucial yet unrealistic way by the fact that consumers are (too) extremely price-sensitive. Chen and Rosenthal therefore model price competition as a stochastic game in which a state represents a certain proportion of the consumer population that is 'loyal' to a firm. If prices are unequal, there is a shift in consumer loyalty from the higher price firm to the lower price firm. This shift occurs deterministically and at a constant rate. Our model can thus be seen as an extension of theirs, as we assume that a price reduction should be treated as an investment with an uncertain but possibly positive long-term effect. This way, the timetradeoff is not only reversed as compared to traditional repeated Bertrand competition, but also stripped of its rigid deterministic component. We are able to confirm some of Chen and Rosenthal's results, in particular that, the greater consumer loyalty (in our model represented by transition probabilities and the distances between neighbouring states), the less intense the price competition. Furthermore, we can confirm and, in addition, provide some more intuition to the fact that in some cases, asymmetric discount factors can lead to a lower normalized profit for the more patient firm. The higher the discount factor for a firm, the more attractive 
it becomes for this firm to choose the low price for offensive reasons. The less patient firm anticipates this by putting more weight on playing the low price itself (for defensive reasons), thereby decreasing the offensive incentives of the more patient firm. Finally, unlike Chen and Rosenthal, our simple but intuitively general setting allows us to provide a full specification of the set of stationary subgame perfect equilibria.

In Radner (2003), demand is 'viscous', by which is meant the notion that consumers switch slowly over time from a higher price firm to a lower price firm. In a duopoly model, Radner is able to prove the existence of a specific family of stationary equilibria. In our model, we focus less on the exact process of how consumers 'flow' from one firm to the other. Instead, like Chen and Rosenthal, we concentrate on the decision problem the firms face, and are consequently able to acquire a deeper understanding of the qualitative impact the changed time-tradeoff has on firms' pricing behavior. Our results confirm Radner's insight that in such situations, competitive outputs might mimic collusive behavior. Furthermore, we find more results on when to expect low prices or mixed behavior in stationary strategies.

The paper proceeds as follows. In the next section, we present our model of dynamic price competition with endogenous market share transitions. In Section 3, we restrict attention to the version of the model that has just one competitive state. This is the most concise and analytically tractable version of the model. Within this limited framework we are able to derive some of the main properties of the general model. Moreover, we are able to make some behavioral inferences by investigating the influence of the discount factor on the firms' incentives. In Section 4 we show illustrating examples that provide extra intuition behind the results presented in Section 3. Next, in Section 5, we add two more competitive states. Within this framework we are able to illustrate some of the interesting market share dynamics that are induced by equilibria of our general model. Finally, in Section 6 , we generalize the main equilibrium properties found in the earlier sections for the full version of our model. In the final section, we discuss the scope of applicability of our model, and hence our results.

\section{General framework}

Two duopolists are repeatedly involved in price competition over a discrete infinite time horizon with possibly varying market circumstances. Market circumstances are captured by the state space, consisting of a finite number of states representing market share divisions between the two firms (shares add up to 1). Besides competitive states in which both firms have a positive market share there are also monopolistic states in which one firm serves the full demand. We assume that the two monopolistic states are absorbing; that is, once a firm has reached a state in which it serves the full market it will continue as a monopolist and 
the opponent has no possibility to regain demand. ${ }^{3}$ For simplicity, we assume for our state space a set of equidistant states: $S=\left\{\left(\frac{k}{K}, 1-\frac{k}{K}\right) \mid k=0,1, \ldots, K\right\}$. We denote the state $\left(\frac{k}{K}, 1-\frac{k}{K}\right)$ by $s_{k}$.

Each period, in common knowledge of the present state, the firms simultaneously and independently set prices. Chosen prices have an immediate impact on the profits earned and a delayed effect on the state dynamics. To keep analyses tractable, in our model, we only allow firms to choose between two prices: a high price (action $H$ ) and a low price (action $L) .{ }^{4}$ The instantaneous profit of a firm equals its market share times $h$ or $\ell$ (with $h>\ell>0$ ), depending on the firm choosing action $H$ or $L$ respectively. In particular, a chosen price has no immediate impact on current sales and hence our model explicitly assumes consumers to be inert. Regarding the consequences for state dynamics, no change in market share division will occur in case the firms choose identical prices. However, in case the firms choose different prices there is a probability that in next period competition resumes in the state where the firm with the lower price has gained $\frac{1}{K}$ in market share. ${ }^{5}$ With the remaining probability mass the process resumes in the same state. Hence, from a state $s_{k}$ (with $k=1, \ldots, K-1$ ) only the states $s_{k-1}$ and $s_{k+1}$ are directly accessible. We allow firms to randomize their behavior by application of a mixed action. Expected profits and transitions are defined in the usual multilinear fashion.

The competition proceeds as follows. In each period both firms observe the current market share division and decide on their respective prices to charge. Next, depending on the prices chosen, both firms observe the actions chosen and receive their profit. Then the transition of market share divisions for the next period is realized. In the next period, the realized market share is observed by the firms and, again, they have to decide on the price to charge. This procedure continues ad infinitum. At each period firms aim to maximize the present value of the future stream of (expected) profits, discounted by application of the discount factor $\delta \in[0,1)$.

Firms are in each period facing the tradeoff between current profits and future market shares. On the one hand there is the incentive to exploit currently installed market share by setting a high price (harvesting incentive). On the other hand there is the incentive to set

\footnotetext{
${ }^{3}$ In Section 4 we show by means of an example that our results also hold when monopoly states are nonabsorbing. In the Concluding Remarks we provide a further discussion why this assumption is non-critical for the qualitative predictions that we derive in this paper.

${ }^{4}$ In this, we distinct from Chen and Rosenthal (1996), where a continuum of prices are allowed. Noteworthy is that as far as our results are comparable to theirs, they are consistent. This provides some evidence of the robustness of our findings with respect to the action space. An advantage of restricting the action space is that it allows providing a characterization of the full set of stationary subgame perfect equilibria (Chen and Rosenthal study only one equilibrium, where their model may possess multiple equilibria). Moreover, our setting produces insightful best response correspondences.

${ }^{5}$ Notice that this approach is in essence identical to an overlapping generations approach with newborn and dying consumers, and where consumers are assumed to behave strategically, though often myopically (cf. Farrell and Shapiro, 1988; Beggs and Klemperer, 1992; Burdett and Coles, 1997; and Cabral, 2007).
} 
a low price, thereby foregoing immediate profit opportunities in exchange for an increased future market share (investment incentive). There are, however, two prominent motives for low pricing. First, a firm may price low in an attempt to increase market share or even to obtain a monopoly position (offensive motive). Second, a firm could as well price low to avoid loss of market share and in the extreme case bankruptcy (defensive motive).

The model we study is contained in the class of finite discounted stochastic games and we adopt the conventional concepts and methods in our analyses. The most general kind of strategy that a firm can formulate in this model is a behavior strategy, where decisions (mixed actions) are conditioned on time, state, and full history of all states visited and all actions being chosen. A pair of behavior strategies constitutes a Nash equilibrium if given the initial state neither of the two firms can achieve an improvement in present value by a unilateral deviation to another behavior strategy. When there does not exist any combination of time, state, and history where a firm can achieve such an improvement, then the Nash equilibrium is called subgame-perfect.

One particular type of behavior strategy that firms can employ are stationary strategies, where decisions (mixed actions) are independent of time and history, and hence conditioned on state only. A pair of stationary strategies that constitutes a (subgame-perfect) Nash equilibrium is called a stationary (subgame-perfect) equilibrium. Since a firm always has a stationary best response against a stationarily behaving opponent (Blackwell, 1962), for the validation of a given pair of stationary strategies to form an equilibrium, only stationary deviations have to be considered. For finite discounted stochastic games in general, and our model in particular, a stationary subgame-perfect equilibrium is guaranteed to exist (Fink, 1964; Takahashi, 1964; Sobel 1971; Herings and Peeters, 2004).

In this paper we focus on stationary subgame-perfect equilibria. Several motivations for this can be found in Maskin and Tirole (2001). Stationary strategies prescribe the simplest form of behavior that is consistent with rationality, stationarity captures the notion that 'bygones are bygones' more completely than does the concept of subgame-perfect equilibrium, and it embodies the principle that 'irrelevant causes should have no effects', that is, only those aspects of the past that are 'significant' should have an appreciable influence on behavior. The pragmatic motivations they give are that in applied theory the focus on stationary strategies allows for clean, unobstructed analysis of the influence of the state variables, that stationary strategies substantially reduce the number of parameters to be estimated in dynamic (econometric) models, and that stationary models can be simulated efficiently. 


\section{When there is just one competitive state}

In this section we consider the situation where there is one competitive state, in which firms have an equal market share. We analyze the symmetric case where the (exogenously given) probabilities to reach the (absorbing) monopolistic states are equal for the firms. This case is graphically illustrated in Figure 1. The situation with asymmetric transition probabilities is considered in two examples in Section 4. These examples will provide more insight in the precise incentives and motives underlying the firms' behavior.

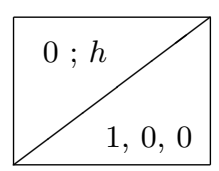

state $(0,1)$

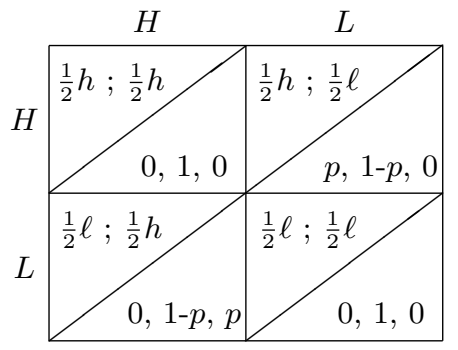

state $\left(\frac{1}{2}, \frac{1}{2}\right)$

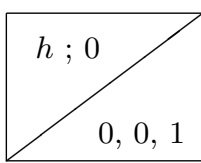

state $(1,0)$

Figure 1: The symmetric model with one competitive state.

The game in Figure 1 contains three states; one competitive state (state $\left(\frac{1}{2}, \frac{1}{2}\right)$ ) and two absorbing monopolistic states in which one of the firms has captured the entire market (state $(0,1)$ and state $(1,0))$. Starting in the competitive state, firms simultaneously and independently choose an action, $L$ or $H$. In this state, sales are assumed to equal $1 / 2$ for both firms. Moreover, costs of production are normalized to 0 and fixed costs are absent. As a result, depending on whether firms opted for $H$ or $L$, profits in the competitive state are respectively given by $\frac{1}{2} h$ or $\frac{1}{2} \ell$ (with $h>\ell>0$ ). In addition to the immediate profits, the actions chosen have consequences for the state dynamics. If both firms choose the same action, then play resumes with probability 1 in the competitive state. If firm $i$ chooses $L$ and its rival chooses $H$, then play resumes with probability $p \in(0,1]$ in the absorbing state in which firm $i$ is a monopolist. With probability $1-p$, play resumes in the competitive state. In the monopolistic state, the surviving firm earns a profit of $h$ every period.

Obviously, considered as a one-shot game (or when the firms are myopic: $\delta=0$ ), there is a unique Nash equilibrium in dominant actions in which both firms choose the high price. Since this equilibrium leads to the highest payoff in the payoff matrix, the Folk theorem implies that this is also the only Nash equilibrium payoff when this game is played repeatedly. This particular situation is induced when $p$, the probability to transit to a monopolistic state in case of unequal prices, is zero. Things change drastically however when this probability is positive. The following proposition provides for all possible values of $h, \ell, p$, and $\delta$ a complete 
specification of the stationary subgame-perfect equilibria. The notation $[x ; y]$ refers to the situation where firm 1 (2) plays action $H$ with probability $x(y)$. We also use $[H ; H]$ and $[L ; L]$ to indicate strategy pairs $[1 ; 1]$ and $[0 ; 0]$ respectively.

Proposition 1. The stationary subgame-perfect equilibria are as given in Table 1. In this

\begin{tabular}{lcccc}
\hline discount factor & $\begin{array}{c}\text { symmetric } \\
\text { and pure }\end{array}$ & $\begin{array}{c}\text { symmetric } \\
\text { and mixed }\end{array}$ & $\begin{array}{c}\text { asymmetric } \\
\text { and pure }\end{array}$ & $\begin{array}{c}\text { asymmetric } \\
\text { and mixed }\end{array}$ \\
\hline $0 \leq \delta<\delta_{1}$ & {$[1 ; 1]$} & & & \\
$\delta=\delta_{1}$ & {$[1 ; 1]$} & {$\left[\sigma^{+} ; \sigma^{+}\right]=\left[\sigma^{-} ; \sigma^{-}\right]$} & & \\
$\delta_{1}<\delta<\delta_{2}$ & {$[1 ; 1]$} & {$\left[\sigma^{+} ; \sigma^{+}\right]$and $\left[\sigma^{-} ; \sigma^{-}\right]$} & & {$\left[\sigma^{+} ; \sigma^{-}\right]$and $\left[\sigma^{-} ; \sigma^{+}\right]$} \\
$\delta=\delta_{2}$ & {$\left[\sigma^{+} ; \sigma^{+}\right]=[1 ; 1]$} & {$\left[\sigma^{-} ; \sigma^{-}\right]=\left[\frac{1}{2} ; \frac{1}{2}\right]$} & {$[t ; 1]$ and $[1 ; t]$ for $0 \leq t \leq \frac{1}{2}$} \\
$\delta_{2}<\delta<\delta_{3}$ & & {$\left[\sigma^{-} ; \sigma^{-}\right]$} & {$[0 ; 1]$ and $[1 ; 0]$} & \\
$\delta=\delta_{3}$ & {$\left[\sigma^{-} ; \sigma^{-}\right]=[0 ; 0]$} & & & {$[t ; 0]$ and $[0 ; t]$ for $0 \leq t \leq 1$} \\
$\delta_{3}<\delta<1$ & {$[0 ; 0]$} & & & \\
\hline
\end{tabular}

Table 1: The stationary subgame-perfect equilibria of the symmetric model with one competitive state.

table the probabilities $\sigma^{+}$and $\sigma^{-}$are given by:

$$
\sigma^{+}=\frac{(1-\delta)(h-\ell)+2 p \delta h+\sqrt{\left.((1-\delta)(h-\ell)+2 p \delta h)^{2}-8(1-\delta) h((1-\delta)(h-\ell)-p \delta \ell)\right)}}{4 p \delta h}
$$

and

$$
\sigma^{-}=\frac{(1-\delta)(h-\ell)+2 p \delta h-\sqrt{\left.((1-\delta)(h-\ell)+2 p \delta h)^{2}-8(1-\delta) h((1-\delta)(h-\ell)-p \delta \ell)\right)}}{4 p \delta h} .
$$

The three threshold values of the discount factor are given by:

$$
\delta_{1}=\frac{(7 h+\ell)(h-\ell)+2 p h(h+\ell)-4 p h \sqrt{h(2 h-\ell)}}{(7 h+\ell)(h-\ell)+4 p h((1-p) h+\ell)}, \quad \delta_{2}=\frac{h-\ell}{h-\ell+p h}, \quad \text { and } \quad \delta_{3}=\frac{h-\ell}{h-\ell+p \ell} .
$$

Moreover, $0<\delta_{1}<\delta_{2}<\delta_{3}<1$.

Proof. Given that the opponent selects the high price with probability $\sigma$ in a stationary fashion, the present values (derived from the Bellman equations) corresponding to the two pure stationary responses are:

$$
\left\{\begin{array}{l}
V_{H}=\frac{1}{2} h+\delta\left\{\sigma V_{H}+(1-\sigma)(1-p) V_{H}\right\} \\
V_{L}=\frac{1}{2} \ell+\delta\left\{\sigma\left(p \frac{h}{1-\delta}+(1-p) V_{L}\right)+(1-\sigma) V_{L}\right\} .
\end{array}\right.
$$

Solving this system yields

$$
V_{H}=\frac{h}{2(1-\delta(1-p+\sigma p))} \quad \text { and } \quad V_{L}=\frac{(1-\delta) \ell+2 \sigma p \delta h}{2(1-\delta)(1-\delta(1-\sigma p))} .
$$

If $V_{H}$ is larger/smaller than $V_{L}$, the firm's optimal response is to adopt the high/low price. The firm is indifferent between the two prices precisely when $V_{H}=V_{L}$. The equation $V_{H}=V_{L}$ is quadratic in $\sigma$ and hence has at most two solutions in the unit interval. The solutions for $\sigma$ 
are precisely the values of $\sigma^{+}$and $\sigma^{-}$given in the proposition. The threshold values for the discount factor $\delta_{1}, \delta_{2}$, and $\delta_{3}$ are attained when $\sigma^{+}=\sigma^{-}, \sigma^{+}=1$, and $\sigma^{-}=0$ respectively. Since $h>\ell>0$ and $p>0$, we have $0<\delta_{1}<\delta_{2}<\delta_{3}<1$.

Despite having only a few number of parameters, the model possesses an interesting equilibrium pattern. Figure 2 graphically illustrates the equilibrium pattern for fixed values of $h, \ell$ and $p$ and different values of the discount factor $\delta$ (in the near-far direction). The stationary strategy of firm 1 (the row-player) is depicted on the vertical axis and that of firm 2 (the column-player) on the horizontal axis. Figure 3 highlights the symmetric equilibria with the

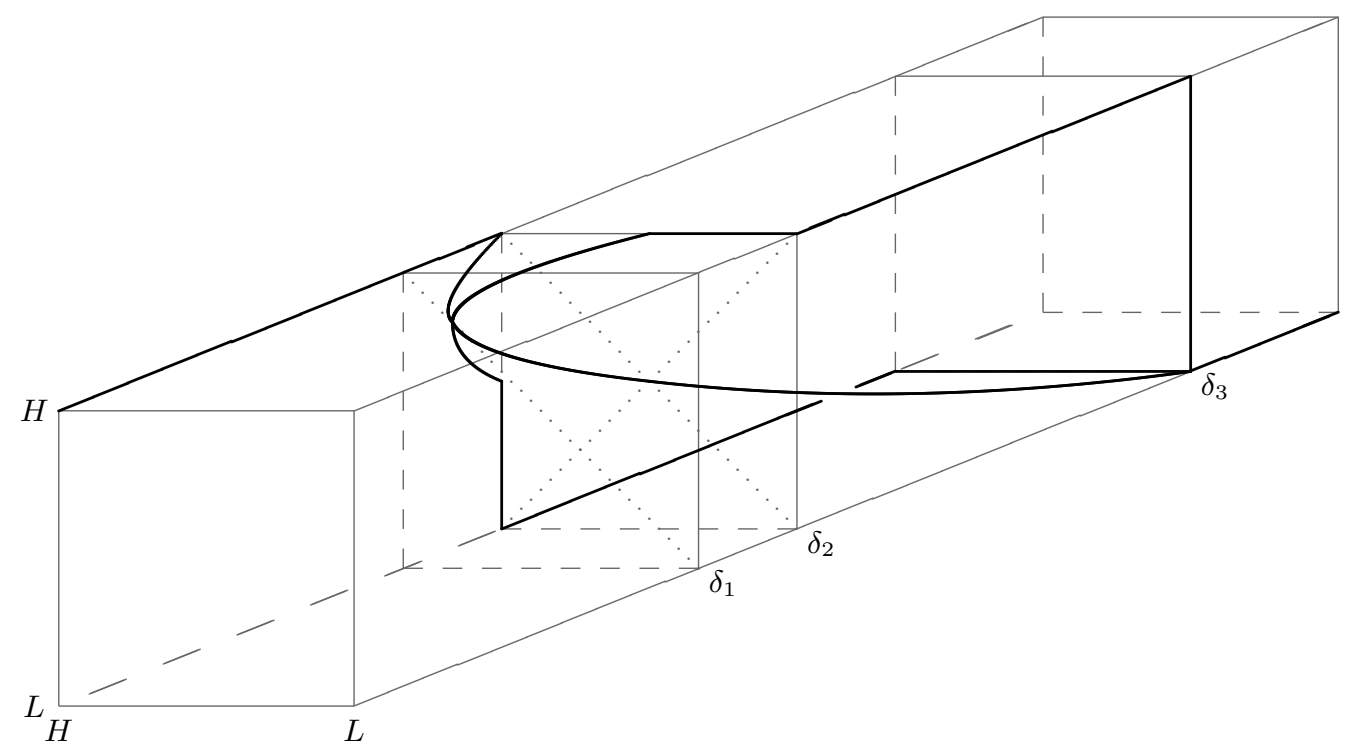

Figure 2: The stationary subgame-perfect equilibria of the symmetric model with one competitive state.

discount factor on the horizontal axis and the common stationary strategy of firms 1 and 2 on the vertical axis.

From the proposition and both figures it becomes apparent that the existence of a particular type of equilibrium heavily depends on the precise value of the discount factor. It is the discount factor that influences the tradeoff between current profits (harvesting incentive) and future market share (investment incentive). For each of the seven configurations listed in the proposition, the corresponding incentive and best response structures and resulting equilibrium configurations are illustrated in Appendix A in detail. The best response curves provide insight in the motives underlying aggressive pricing.

Offensive motives to set a low price are totally absent when the opponent sets the low price with probability one and are increasing in the probability by which the opponent selects 


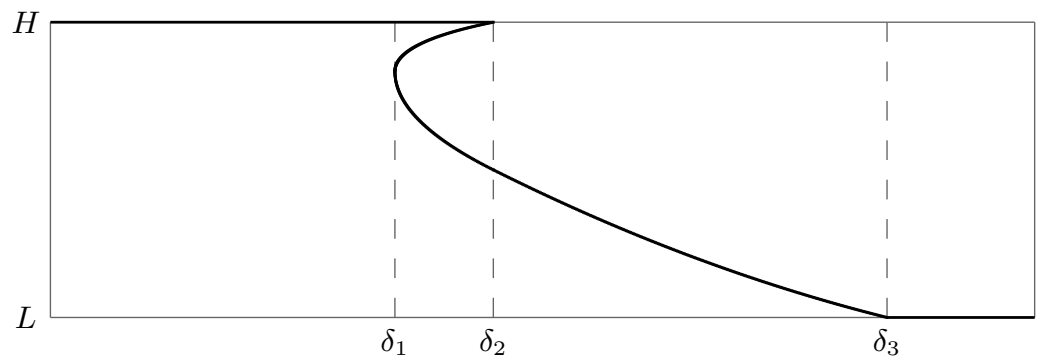

Figure 3: The symmetric stationary subgame-perfect equilibria of the symmetric model with one competitive state.

the high price. For defensive motives the opposite holds: they are absent when the opponent sets the high price with probability one and are increasing in the probability by which the opponent sets the low price. Both motives mutually play a role in the best response for a firm when the opponent randomizes its pricing decision and become more substantial when the discount factor and hence the investment incentives increase.

For low values of the discount factor $\left(\delta<\delta_{1}\right)$, none of the firms regards an opportunity of monopolization sufficiently attractive to forego current profits; neither would any of the firms ever set a low price in order to prevent monopolization by the opponent. The low discount factor simply eliminates any interest in future market share: the investment incentives are too weak to provide an incentive for aggressive pricing. This results in a unique stationary subgame-perfect equilibrium in which both firms exploit installed market share by setting a high price. For sufficiently large discount factors $\left(\delta>\delta_{2}\right)$, the high price outcome $[H ; H]$ fails to be an equilibrium, although it is the unique (subgame-perfect) Nash equilibrium prediction of the one shot game (when $\delta=0$ ) and the repeated game (when $p=0$ ).

For high values of the discount factor $\left(\delta>\delta_{3}\right)$, both firms select the low price. Both the offensive and the defensive motive apply here: firms would grasp any opportunity for monopolization and would prevent against any hostile attempt for monopolization. The high discount factor has changed the firms' focus totally towards future market share. This results in a unique stationary subgame-perfect equilibrium in which both firms set a low price.

For intermediate values of the discount factor $\left(\delta_{1}<\delta<\delta_{3}\right)$, firms do not possess a dominant strategy and may consider both prices a feasible action to choose. Although offensive and defensive motives are mutually in force and even interact, the decisive motive for setting a low price appears to change in a subtle manner at $\delta=\delta_{2}$.

For intermediate values of the discount factor less than $\delta_{2}$, firms respond to high prices with high prices. This indicates that in the ideal situation to conduct an offensive act, firms would refuse to do so. This explains the persistence of the high price outcome as an equilib- 
rium. Moreover, firms also respond to low prices with high prices. This indicates that in the most threatening situation, firms do not protect current market share: the firm accommodates a fight by the opponent. However, firms do respond with the low price in case the opponent chooses the high price with a probability larger than $\sigma^{-}$but less than $\sigma^{+}$. When the probability exceeds $\sigma^{+}$, the probability on the opponent's success in achieving a monopoly position is not sufficiently threatening and the defensive motives have become insignificant. When the probability falls below $\sigma^{-}$, the own probability on a successful monopolization becomes too small to offset the costs of an immediate loss in profits and the offensive motives have become insignificant. This explains the four mixed equilibria that result from the combinations of mixing with $\sigma^{-}$and $\sigma^{+}$.

For intermediate values of the discount factor larger than $\delta_{2}$, firms respond to high prices with low prices, which clearly hints at an offensive act. Once the opponent chooses the low price with a probability sufficiently large (larger than $1-\sigma^{-}$), once again the probability of acquiring the dominant position becomes too small to continue fighting. This precisely explains the existence of the two asymmetric pure equilibria: high prices are responded by low prices, and vice versa. In addition, there is one symmetric mixed equilibrium where both firms choose the high price with the probability that makes the opponent indifferent between attacking or not.

Corollary 2. High price equilibria only exist for low values of the discount factor $\left(\delta \leq \delta_{2}\right)$ and low price equilibria only for high discount factors $\left(\delta \geq \delta_{3}\right)$. Moreover, these equilibria never co-exist and there is a proper interval of discount values $\left(\delta \in\left(\delta_{2}, \delta_{3}\right)\right)$ for which neither of these two outcomes constitutes an equilibrium.

Although these statements are formulated as a corollary to Proposition 1, they refer to general properties of our framework. The generalization of these statements are the topic of Section 6 .

Notice that the behavioral implications of our model oppose that of the standard literature where high prices (collusion) are only sustainable for high discount factors. The main cause of this conversion of implications is the flip in time-tradeoff. In contrast to our framework, in the standard models of repeated price competition with application of trigger strategies the lower (undercutting) price results in a capturing of the entire market and hence higher instantaneous profit, but in a lower future profit due to the reversal to profit eroding price competition. Our findings show that the main insights from textbook models are not valid in presence of demand inertia (consumers need time to learn about (differences in) prices), consumer loyalty, switching costs, or short-term contracts when no overly sophisticated behavior like threats or triggers are assumed. Notice that high prices are even not sustainable as an equilibrium by means of trigger strategies for sufficiently high discount factors when $p>\frac{h-\ell}{2 h-\ell}{ }^{6}$

\footnotetext{
${ }^{6}$ Proof. Suppose $\delta>\delta_{3} \equiv \frac{h-\ell}{h-\ell+p \ell}$ such that in case of a deviation firms can revert to the unique stationary
} 
For discount factors between the threshold values $\delta_{1}$ and $\delta_{3}$, equilibria exist that imply monopolization in the long run. There are three types of equilibria in which such monopolization is possible: asymmetric equilibria in pure strategies when $\delta \in\left[\delta_{2}, \delta_{3}\right]$, symmetric ones in mixed strategies when $\delta \in\left[\delta_{1}, \delta_{3}\right]$, and asymmetric ones in mixed strategies when $\delta \in\left(\delta_{1}, \delta_{2}\right] \cup\left\{\delta_{3}\right\}$.

Corollary 3. Monopolization can occur on the equilibrium path unless the discount factor is very low or very high $\left(\delta_{2} \leq \delta \leq \delta_{3}\right)$.

There are two factors in our model that are related to the liquidity of the market, i.e. the difficulty of attracting extra demand. First, the probability of going to another state $p$ is an indicator of the likelihood that a price reduction will succeed in attracting more demand and could be seen as a measure of consumer loyalty. We see that a decrease of $p$ towards zero induces an increase in $\delta_{2}$ and $\delta_{3}$ to one and hence the maximum value of the discount factor for which we only have a stationary subgame-perfect equilibrium with high prices. Second, the difference between the high and low immediate profits $h-\ell$ is an indicator of the minimum investment necessary to get any consumers moving and could be seen as a measure of the importance of switching costs. We see that a decrease of $h-\ell$ towards zero induces a decrease in $\delta_{2}$ and $\delta_{3}$ towards zero and hence the minimum value of the discount factor for which we only have a stationary subgame-perfect equilibrium with low prices. Thus, when consumer loyalty is high or when high switching costs are involved, firms may be expected to set high prices. Moreover, when $\ell$ vanishes $\delta_{3}$ gradually increases to one and hence the minimum value of the discount factor for which we only have a stationary subgame-perfect equilibrium with low prices. The following corollary summarizes these equilibrium properties for limiting cases of our model.

Corollary 4. (i) $[H ; H]$ is the unique equilibrium if $p=0$. (ii) $[L ; L]$ is the unique equilibrium if $h=\ell$. (iii) $[L ; L]$ never constitutes an equilibrium if $\ell=0$.

The first statement in the corollary implies that only high prices are chosen when monopolization is impossible by construction and hence investment incentives have disappeared. The second statement indicates that when harvesting incentives disappear only low prices are chosen. Finally, the third statement indicates that when the low price is associated with marginal cost pricing, the best response to the opponent setting the low price is to set the high price.

subgame-perfect equilibrium $[L ; L]$. Now, $[H ; H]$ is sustainable as a subgame-perfect Nash equilibrium if and only if $\frac{1}{2} h \frac{1}{1-\delta} \geq \frac{1}{2} \ell+\delta\left(p h \frac{1}{1-\delta}+(1-p) \frac{1}{2} \ell \frac{1}{1-\delta}\right)$; or equivalently $\delta \leq \delta^{*} \equiv \frac{h-\ell}{p(2 h-\ell)}$. Hence, $[H ; H]$ is not sustainable as an equilibrium when $\delta>\max \left\{\delta_{3}, \delta^{*}\right\}$. For this condition to be feasible, $\delta^{*}$ should be less than 1 , which is the case if and only if $p>\frac{h-\ell}{2 h-\ell}$. 


\section{$4 \quad$ Illustrating Examples}

In this section we provide some further intuition behind the results derived above. We do this by means of illustrating examples. The first example discusses comparative statics properties of the symmetric stationary subgame-prefect equilibrium when a small asymmetry in the exogenous monopolization strategies is introduced.

Example (asymmetric monopolization probabilities). Take as parameter specifications $h=5, \ell=3, p=0.25$, and $\delta=0.6713$ (as in the fifth case in the Appendix). In the unique symmetric stationary subgame-perfect equilibrium both firms choose the high price with probability 0.1440 . Every period each firm has a probability of 0.0308 to obtain a monopoly position in the subsequent period. Moreover, each firm has a present value of 5.29.

Next, we consider the asymmetric situation where the exogenously given probability to become monopolist in case of solely opting for the low price increases to 0.3 for firm 1 . The equilibrium moves to the event where firm 1 chooses the high price with probability 0.0437 and firm 2 chooses this price with probability 0.1084 . Now, every period firm 1 has a probability of 0.0312 to obtain a monopoly position in the subsequent period, while this probability is 0.0097 for firm 2. Moreover, the present value of firm 1 decreases to 5.23 while that of firm 2 decreases to 4.80 .

We see that in response to an increase in firm 1's exogenously given probability on a successful monopolization, both firms increase the probability by which they select the low price - this increase being more substantial for firm 1 than for firm 2. For firm 1 the motive is clearly offensive, while for firm 2 the motive is defensive. Only for firm 1 the increase in competitiveness leads to an increase in the probability of becoming monopolist in the subsequent period; for firm 2 it even decreases. Both firms do suffer from the increase in competitiveness in terms of present value.

We provide another example in which the asymmetry in the previous example is pushed to the extreme. This extreme case disentangles the offensive and defensive motives for aggressive pricing behavior, since for each of the firms one of the motives is excluded by construction.

Example (offensive versus defensive motives). Suppose the probability of a successful monopolization for firm 1 when it sets a lower price is equal to one, while for firm 2 this probability is zero. In this situation, by construction, firm 1 only opts for the low price out of offensive motives, while firm 2 only opts for the low price out of defensive reasons. Table 2 provides a specification of the equilibria corresponding to all different values of the discount factor. 


\begin{tabular}{lc}
\hline discount factor & sspe \\
\hline $0 \leq \delta<\frac{h-\ell}{2 h-\ell}$ & {$[1 ; 1]$} \\
$\delta=\frac{h-\ell}{2 h-\ell}$ & {$[t ; 1]$ for $0 \leq t \leq 1$} \\
$\frac{h-\ell}{2 h-\ell}<\delta<\frac{h-\ell}{h}$ & {$[0 ; 1]$} \\
$\delta=\frac{h-\ell}{h}$ & {$[0 ; t]$ for $\frac{(1-\delta)(h-\ell)}{\delta h} \leq t \leq 1$} \\
$\frac{h-\ell}{h}<\delta<1$ & {$\left[\frac{\ell-(1-\delta) h}{\delta \ell} ; \frac{(1-\delta)(h-\ell)}{\delta h}\right]$} \\
\hline
\end{tabular}

Table 2: The stationary subgame-perfect equilibria of the model in the example.

First, firm 1 will always respond to a low price with a high price. Hence, $[L ; L]$ does not constitute an equilibrium for any value of the discount factor; in particular also not for values near 1. The intuition behind this is as follows. By setting the low price, firm 2 eliminates any opportunity for firm 1 to monopolize the market and thereby firm 1's offensive motives for setting the low price. Since there is, by construction, also no defensive motive for firm 1 to opt for the low price, firm 1 will never respond to a low price with a low price. Second, we see that the firm with offensive intensions (firm 1) turns to a low price already for lower values of the discount factor than the firm with defensive intensions (firm 2). Third, the probability by which firm 1 (firm 2) sets the high price increases (decreases) to one (zero) when the discount factor approaches one. Hence, for high discount factors, the firm that can lose clientele behaves more aggressively in order to defend itself against this threat.

Chen and Rosenthal (1996) shows that a more patient firm might end up with a lower normalized discounted profit. This effect can be nicely shown using the best-response correspondences provided in the appendix and explained through the incentives present in this model.

Example (lower normalized profit for the more patient firm). Like in Appendix A, we fix the following parameters: $h=5, \ell=3$ and $p=0.25$. With these parameters, the three threshold values of the discount factor are $\delta_{1}=0.6052, \delta_{2}=0.6154$ and $\delta_{3}=0.7273$. We look at a situation in which both firms have a discount factor $\delta=0.6713$ and a situation in which firm 2 has a slightly higher discount factor of $\delta=0.7$. Figure 4 shows how the best response correspondences change when we move from the symmetric situation to the situation in which firm 2 has a slightly higher discount factor.

As one can see, if firm 2 (whose strategy is depicted on the horizontal axis) has a higher discount factor (i.e. is more patient), firm 1 puts more weight on playing the low price (0.943 instead of 0.856 ), while firm 2 chooses the same strategy as it would in the symmetric situation. Since, ceteris paribus, one's (normalized) discounted profit always decreases if the opponent puts more weight on $L$, we see that being more patient can indeed decrease one's profits in this mixed equilibrium (in this situation from 1.74 to 1.61). The rationale behind this can be explained as follows. In a mixed equilibrium, both firms choose in such a way that the other 


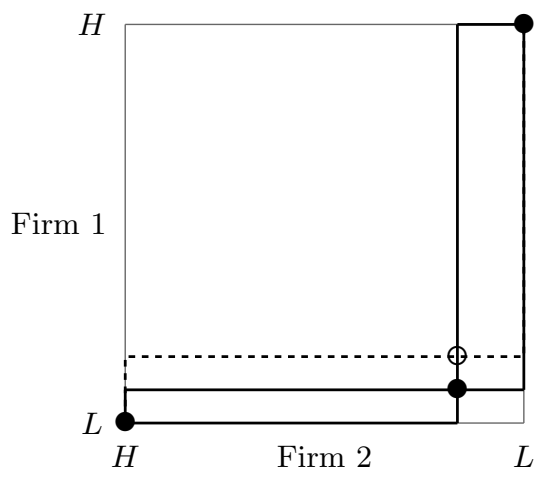

Figure 4: A more patient firm can have a lower normalized payoff.

firm is willing to randomize between the available actions. If a firm's discount factor goes up, it attaches more value to future payoffs and would therefore be more inclined to choose a low price for offensive reasons. Therefore, the other firm should reduce these incentives by making it less likely that a price reduction will succeed to increase in future profits. It accomplishes exactly this by putting more weight on the low price itself (for defensive reasons), thereby making the more patient firm indifferent between playing the high or the low price.

The final example shows that making the monopoly states non-absorbing does not change the structure of our stationary subgame-perfect equilibria.

Example (non-absorbing monopoly states). Suppose that the two monopolistic states are no longer absorbing but that instead with a probability $q$ the system returns to the 'competitive' state in case the monopolist chooses a high price and its challenger indicates a low price. Figure 5 graphically illustrates this situation.

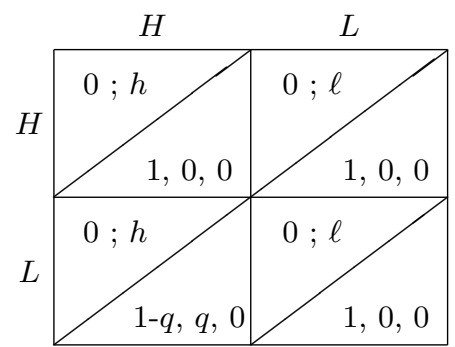

state $(0,1)$

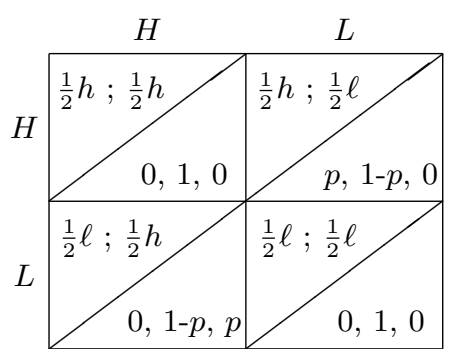

state $\left(\frac{1}{2}, \frac{1}{2}\right)$

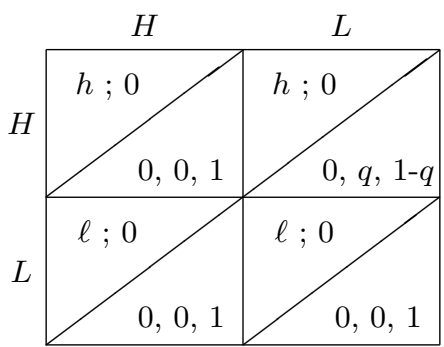

state $(1,0)$

Figure 5: Nonabsorbing monopoly states.

Take the following parameter setting: $h=5, \ell=3, p=0.25$ and $q=0.25$. If we focus on the 'competitive' state, we find that the same threshold levels for the discount factor exist as in the setting with absorbing monopoly states: for all discount factors between 0 
and $\delta_{1}=0.713$ there is a unique stationary subgame-perfect equilibrium where both firms choose the high price. Between $\delta_{1}$ and $\delta_{2}=0.727$ we have four mixed equilibria next to the pure high price equilibrium. Between $\delta_{2}$ and $\delta_{3}=0.842$ we have one mixed equilibrium and the two asymmetric pure equilibria. For discount factors higher than $\delta_{3},[L ; L]$ is the unique stationary subgame-perfect equilibrium.

\section{Market share dynamics}

Due to the absorbing nature of the monopolistic states, the three state model of the previous section does not facilitate any market share dynamics. Therefore, in this section, we will consider the symmetric model with five states as presented in Figure 6 . In addition to the state where both firms have equal market share and the two monopoly states, there are two states where both firms have positive but different market shares. From these states, both the state with equal market share and the state where the firm with larger market share obtains a monopoly position are reachable. The additional feature captured in this five state model relative to the three state model is that competitive play continues once the firms leave the symmetric state in which they both serve half of the market. In other words, when the balance is broken and one firm has acquired a dominant position, it is possible for the dominated firm to recapture the lost market share.
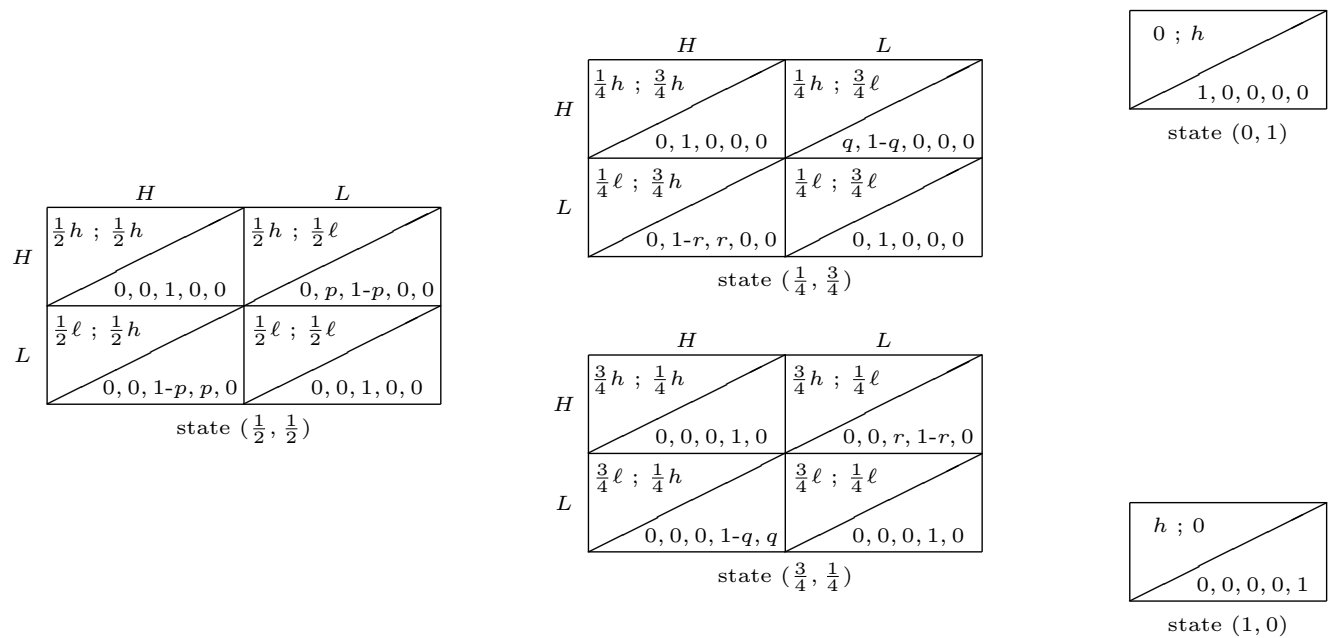

Figure 6: The symmetric model with five states.

We restrict our attention to the symmetric pure stationary subgame-perfect equilibria, where a pair of stationary strategies is called symmetric if for all states the firms' actions specified by the strategy are mirrored when market shares are mirrored. By $[x y z]$ we denote the symmetric pair of strategies where firm 1 (2) chooses action $x, y$ and $z(z, y$ and $x)$ in state $\left(\frac{1}{4}, \frac{3}{4}\right),\left(\frac{1}{2}, \frac{1}{2}\right)$ and $\left(\frac{3}{4}, \frac{1}{4}\right)$ respectively. 
There are three types of equilibria: equilibria in which no state transitions occur $([L L L]$, $[H H H],[L H L]$ and $[H L H])$, equilibria in which firms move to equal market shares $([L L H]$ and $[L H H]$ ) and equilibria that push the market to monopoly $([H L L]$ and $[H H L])$. The following three propositions, each deal with one of these equilibrium types. All equilibria have in common that the symmetric state is 'strategically absorbing', meaning that given the equilibrium strategies play never leaves the symmetric state once it has been reached. This is inherent to the restriction to symmetric pure stationary subgame-perfect equilibria.

Proposition 5. Symmetric pure stationary subgame-perfect equilibria in which all states are strategically absorbing exist when the conditions in Table 3 are met.

\begin{tabular}{lccc}
\hline & Market share 0.25 & Market share 0.5 & Market share 0.75 \\
\hline$[H H H]$ & $\delta \leq \frac{h-\ell}{h-\ell+r h}$ & $\delta \leq \frac{2(h-\ell)}{2(h-\ell)+p h}$ & $\delta \leq \frac{3(h-\ell)}{3(h-\ell)+q h}$ \\
{$[L L L]$} & $\delta \geq \frac{h-\ell}{h-\ell+q \ell}$ & $\delta \geq \frac{2(h-\ell)}{2(h-\ell)+p \ell}$ & $\delta \geq \frac{3(h-\ell)}{3(h-\ell)+r \ell}$ \\
{$[H L H]$} & $\delta \leq \frac{2(h-\ell)}{2(h-\ell)+r(2 \ell-h)}$ & $\delta \geq \frac{2(h-\ell)}{2(h-\ell)+p(2 \ell-h)}$ & $\delta \leq \frac{3(h-\ell)}{3(h-\ell)+q h}$ \\
{$[L H L]$} & $\delta \geq \frac{h-\ell}{h-\ell+q \ell}$ & $\delta \leq \frac{2(h-\ell)}{2(h-\ell)+p(3 \ell-2 h)}$ & $\delta \geq \frac{3(h-\ell)}{3(h-\ell)+r(3 \ell-2 h)}$ \\
\hline
\end{tabular}

Table 3: All states are strategically absorbing.

Proof. Consider the symmetric strategy profile $[L L L]$. For this profile to be an equilibrium no firm should have an incentive to deviate to the high price in any state. So, when a firm has a market share of $\frac{1}{4}$ the condition $\frac{1}{4} \ell \frac{1}{1-\delta} \geq \frac{1}{4} h \frac{1}{1-\delta(1-q)}$ should be satisfied. This condition is equivalent to $\delta \geq \frac{h-\ell}{h-\ell+q \ell}$, the first inequality in the table. The conditions corresponding to market shares $\frac{1}{2}$ and $\frac{3}{4}$ and for the other profiles in this table and those of the next two propositions are obtained in a similar fashion.

The conditions in the table reveal that an equilibrium in which in all states low (high) prices are charged exists when the discount factor is sufficiently high (low). Since the symmetric state is strategically absorbing, the situation in the asymmetric states is strategically equivalent to that in the symmetric state of the three state model of the previous section. Therefore, an explanation of the existence of the other two equilibria for intermediate values of the discount factor boils down to a repetition of earlier arguments.

Proposition 6. Symmetric pure stationary subgame-perfect equilibria in which state dynamics drives to the strategically absorbing symmetric state exist precisely when the conditions in Table 4 are met.

We see that equilibria with a tendency to induce equal market share only exist for intermediate values of the discount factor. In these equilibria, the firms opt for the high (low) price when they have the higher (smaller) market share. This implies that in asymmetric states, the firm with the lower market share has a strong incentive to attack (low price is a best response to 


\begin{tabular}{lccc}
\hline & Market share 0.25 & Market share 0.5 & Market share 0.75 \\
\hline$[L H H]$ & $\delta \geq \frac{h-\ell}{h-\ell+r h}$ & $\delta \leq \frac{2(h-\ell)}{2(h-\ell(1-r)+p h}$ & $\delta \leq \frac{3(h-\ell)}{3(h-\ell)+r(3 \ell-2 h)}$ \\
{$[L L H]$} & $\delta \geq \frac{h-\ell}{h-\ell+r(2 \ell-h)}$ & $\delta \geq \frac{2(h-\ell)}{2(h-\ell)(1-r)+p \ell}$ & $\delta \leq \frac{3(h-\ell)}{3(h-\ell)+r \ell}$ \\
\hline
\end{tabular}

Table 4: Only the symmetric state is absorbing.

high price), while the firm with the larger market share has no incentive to defend (high price is a best response to low price). Notice, however, that the conditions for these profiles to be an equilibrium in the symmetric state are mutually exclusive and hence never co-exist as an equilibrium.

Proposition 7. Symmetric pure stationary subgame-perfect equilibria that push state dynamics to monopolization exist precisely when the conditions in Table 5 are met. In the table, *

\begin{tabular}{lccc}
\hline & Market share 0.25 & Market share 0.5 & Market share 0.75 \\
\hline$[H L L]$ & $\delta \leq \frac{h-\ell}{h-\ell+q \ell}$ & $*$ & $\delta \geq \frac{3(h-\ell)}{3(h-\ell)+q h}$ \\
{$[H H L]$} & $\delta \leq \frac{h-\ell}{h-\ell+q \ell}$ & $* *$ & $\delta \geq \frac{3(h-\ell)}{3(h-\ell)+q h}$ \\
\hline
\end{tabular}

Table 5: Monopolization may result.

and $^{* *}$ refer to the solutions to the quadratic inequalities

$$
\frac{1}{2} \ell \frac{1}{1-\delta} \geq\left(\frac{1}{2} h+\delta p \frac{1}{4} h \frac{1}{1-\delta(1-q)}\right) \frac{1}{1-\delta(1-p)}
$$

and

$$
\frac{1}{2} h \frac{1}{1-\delta} \geq\left(\frac{1}{2} \ell+\delta p\left(\frac{3}{4} \ell+q \frac{\delta}{1-\delta} h\right) \frac{1}{1-\delta(1-q)}\right) \frac{1}{1-\delta(1-p)}
$$

respectively.

Like those of the previous proposition, equilibria with a tendency to induce monopolization only exist for intermediate values of the discount factor. In these equilibria, the firms opt for the low (high) price when they have the higher (smaller) market share. This implies that in asymmetric states, the firm with the higher market share has a strong incentive to fight for the monopoly position (low price is a best response to high price), while the firm with the smaller market share winks (high price is a best response to low price). Given the behavior in the asymmetric competitive states, leaving the symmetric state implies monopolization (sooner or later). Strategically the situation in the symmetric state is therefore not different from that in the model with one competitive state. From this we can conclude that the profiles $[H H L]$ and $[H L L]$ only constitute an equilibrium for sufficiently low and respectively high discount factors and never co-exist as an equilibrium.

On basis of the propositions we can formulate the following corollary, which is parallel to Corollary 2. 
Corollary 8. High price equilibria $([\mathrm{HHH}])$ do only exist for low values of the discount factor and low price equilibria ([LLL]) only for high discount factors. For very low (high) values of the discount factor, the high (low) price equilibrium is unique. Moreover, these equilibria never co-exist and there is a non-degenerate interval of discount values for which none of these two outcomes constitutes an equilibrium.

The following corollary summarizes some properties for limiting cases of the five state model and are easily verified by substitution of the respective limit values in the conditions within the propositions.

Corollary 9. (i) There is no equilibrium in which a firm plays action $L$ when its market share is $\frac{1}{2}$ if $p=0$. (ii) There is no equilibrium in which a firm plays action $L$ when its market share is $\frac{3}{4}$ if $q=0$. (iii) There is no equilibrium in which a firm plays action $L$ when its market share is $\frac{1}{4}$ if $r=0$. (iv) $[L L L]$ is the unique equilibrium if $h=\ell$. (v) There is no equilibrium in which there is a state where both firms choose action $L$ if $\ell=0$.

The first statement implies that firms harvest when an increase in market share is impossible for both firms. The condition in the second (third) statement implies that monopolization (return to the symmetric state) is impossible. Therefore, the only reason for the larger (smaller) firm to set a low price is to avoid loss of market share. However, the threat of loss in market share is only applicable if the opponent with the smaller (larger) market share would set a low price. But, in anticipation of the opponent protecting its high (low) market share, in absence of the possibility to lose market share, the smaller (larger) firm will set a high price. Hence, in equilibrium the larger (smaller) firm will never choose the low price with probability one. The fourth statement indicates that when harvesting incentives disappear only low prices are chosen. Finally, the fifth statement indicates that when the low price is associated with marginal cost pricing, regardless of the state, the best response to the opponent setting the low price is to set the high price.

We finish this section by two examples that reveal interesting market share dynamics to be embodied by the model with five states. The first example focusses on market share dynamics that induces a monopoly with probability one in the long-run; the second example focusses on enduring market share fluctuations to be possible.

Example (monopolization). In general, the market share dynamics induces a monopolistic market in the long-run when the (symmetrically behaving) firms randomize their action in the symmetric state and choose action $H(L)$ with positive probability when they have the smaller (larger) market share in the asymmetric states.

One configuration of parameters for which such behavior is part of a stationary subgameperfect equilibrium is when $h=5, \ell=3.25, p=0.5, q=0.15, r=0.75$ and $\delta=0.7$. In fact, 
there is an equilibrium in which firms select the high price with probability $0.5716,0.0427$ and 0.1099 when the market share is $0.25,0.50$ and 0.75 respectively. Figure 7 presents the Markov chain generated by this equilibrium.

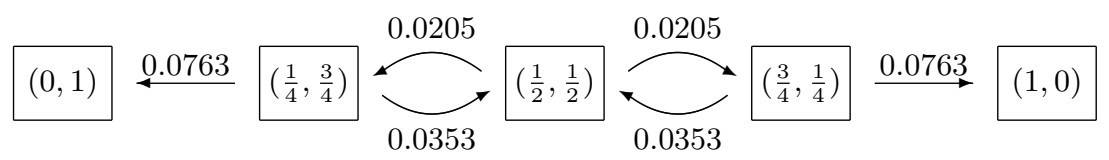

Figure 7: Markov chain resulting in monopolization.

Since firms randomize their action in each state, market shares may fluctuate and stagnate for a while, but inevitably reach one of the absorbing monopolistic states. One property that is easily derived from this Markov chain is that when the process starts in an asymmetric state, the probability that it is the firm with the larger installed base that will ultimately end up as monopolist equals 0.8418 .

Example (enduring market share fluctuations). In general, the market share dynamics induces enduring market share fluctuations when the (symmetrically behaving) firms randomize their action in the symmetric state and choose action $L$ with positive probability when it has the smaller market share and choose action $H$ with positive probability when it has the larger market share in the asymmetric states, with at least one of these probabilities being equal to one.

One configuration of parameters for which such behavior is part of a stationary subgameperfect equilibrium is when $h=5, \ell=3, p=0.7, q=0.4, r=0.5$ and $\delta=0.65$. In fact, there is an equilibrium in which firms select the high price with probability $0.0000,0.7854$ and 1.0000 when the market share is $0.25,0.50$ and 0.75 respectively. Figure 8 presents the Markov chain generated by this equilibrium.

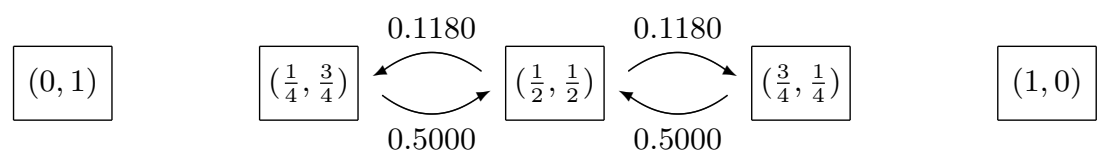

Figure 8: Markov chain giving rise to enduring market share fluctuations.

Since firms randomize their action in the symmetric state, a transition to one of the asymmetric states is expected to materialize in finite time. Once an asymmetric state is reached, the firm with the smaller market share starts fighting for gaining back the lost market share, which the firm with the larger market share accommodates. As a result, the process will eventually return to the state with equal market shares. The invariant distribution over states predicts the system to be in the symmetric state with probability 0.6793 in the 
long-run; with the remaining probability mass the system resists in one of the asymmetric states, each with equal probability.

\section{Generalization of equilibrium properties}

In the previous sections, we examined pure stationary subgame-perfect equilibria on a small number of competitive states and derived conditions for their existence in terms of the discount factor. A special emphasis was placed on high price and low price equilibria, in which firms set the high price or respectively the low price in every state. In this section, we extend our investigation to the situation where the competition between firms is taking place on an arbitrary number of equidistant states $s_{0}, s_{1}, \ldots, s_{K}$, where $s_{k}$ is the state in which firms 1 and 2 have market shares $\frac{k}{K}$ and $1-\frac{k}{K}$ respectively. The transition probabilities when the firms choose different prices are only assumed to be positive. This means that our analysis also includes asymmetric situations.

Proposition 10. Assume that two pure stationary subgame-perfect equilibria co-exist for a certain discount factor. Then, it cannot be the case that in one equilibrium, both firms set the high prices in two neighboring competitive states, whereas in the other equilibrium, both firms set the low prices in these two states.

Proof. Consider two pairs of pure stationary strategies $\sigma=\left(\sigma^{1}, \sigma^{2}\right)$ and $\tau=\left(\tau^{1}, \tau^{2}\right)$ and two neighboring competitive states $s_{k}$ and $s_{k+1}$. Assume that $\sigma$ prescribes the high price for both firms in $s_{k}$ and $s_{k+1}$, whereas $\tau$ prescribes the low price for both firms in $s_{k}$ and $s_{k+1}$. We show that $\sigma$ and $\tau$ cannot co-exist as equilibria for any discount factor. Due to symmetry, we may assume that $k \leq \frac{K}{2}$.

With regard to $\sigma$, firm 1's discounted profit with starting state $s_{k}$ is $\frac{k}{K} h \frac{1}{1-\delta}$. If firm 1 deviates at the first period by setting the low price in state $s_{k}$ and continues with $\sigma^{1}$ afterwards, then its discounted profit becomes $\frac{k}{K} \ell+\delta\left[p \frac{k+1}{K} h \frac{1}{1-\delta}+(1-p) \frac{k}{K} h \frac{1}{1-\delta}\right]$, where $p$ denotes the transition probability from state $s_{k}$ to state $s_{k+1}$ when firm 1 sets a lower price than firm 2 in state $s_{k}$. For $\sigma$ to be an equilibrium, this deviation by firm 1 should not be profitable, which is exactly the case when $\delta \leq \underline{\delta} \equiv \frac{k(h-\ell)}{k(h-\ell)+p h} \cdot{ }^{7}$

With regard to $\tau$, firm 2's discounted profit with starting state $s_{k}$ is $\frac{K-k}{K} \ell \frac{1}{1-\delta}$. If firm 2 deviates at the first period by setting the high price in state $s_{k}$ and continues with $\tau^{2}$ afterwards, then his discounted profit becomes $\frac{K-k}{K} h+\delta\left[p \frac{K-k-1}{K} \ell \frac{1}{1-\delta}+(1-p) \frac{K-k}{K} \ell \frac{1}{1-\delta}\right]$. For $\tau$ to be an equilibrium, this deviation by firm 2 should not be profitable, which is exactly the case when $\delta \geq \bar{\delta} \equiv \frac{(K-k)(h-\ell)}{(K-k)(h-\ell)+p \ell}$.

\footnotetext{
${ }^{7}$ Here we apply the one-shot deviation principle, which states that for the verification of a certain strategy profile to constitute an equilibrium, for all histories (including time and current state) only the impact of one-period deviations have to be considered.
} 
Since $h>\ell$ and $k \leq \frac{K}{2}$ by assumption, it is easily verified that $\underline{\delta}<\bar{\delta}$, and therefore there is no discount factor $\delta$ for which both $\sigma$ and $\tau$ constitute an equilibrium.

The next result follows immediately from the previous proposition (for at least two competitive states) and Corollary 2 (for just one competitive state).

Corollary 11. High price equilibria $([H H \cdots H])$ and low price $([L L \cdots L])$ equilibria cannot co-exist for any discount factor.

We noticed in the previous sections that high price equilibria corresponded to low discount factors, whereas low price equilibria to high discount factors. This holds true in general, as stated in the next proposition.

Proposition 12. There exist threshold values $\delta_{1}, \delta_{2}$ and $\delta_{3}$ for the discount factor such that $0<\delta_{1} \leq \delta_{2}<\delta_{3}$ and the following properties hold:

1. A high price equilibrium $([H H \cdots H])$ exists precisely when the discount factor is at most $\delta_{2}$. Furthermore, if the discount factor is below $\delta_{1}$, then the high price equilibrium is the unique stationary subgame-perfect equilibrium.

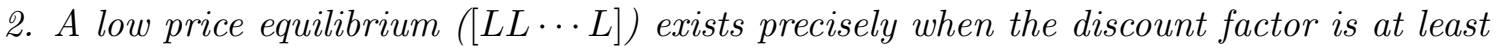
$\delta_{3}$.

Proof. In view of Corollary 11, we only need to show that there exist positive thresholds $\delta_{1}, \delta_{2}$ and $\delta_{3}$ with the above properties. Let $\sigma_{H}^{i}$ and $\sigma_{L}^{i}$ respectively denote the high price strategy and the low price strategy for firm $i$.

1. The existence of $\delta_{1}$. When $\delta=0$, the firms are myopic and choosing the high price is a strictly dominant action in every state. Due to continuity, the high price remains a strictly dominant action on a proper interval $\left[0, \delta_{1}\right]$ of discount factors, and hence $\left(\sigma_{H}^{1}, \sigma_{H}^{2}\right)$ is the unique stationary subgame-perfect equilibrium for all $\delta \in\left[0, \delta_{1}\right]$.

2. The existence of $\delta_{2}$. It is sufficient to show that if $\left(\sigma_{H}^{1}, \sigma_{H}^{2}\right)$ constitutes an equilibrium for a certain discount factor, then $\left(\sigma_{H}^{1}, \sigma_{H}^{2}\right)$ remains an equilibrium for lower discount factors. So, assume that $\left(\sigma_{H}^{1}, \sigma_{H}^{2}\right)$ is an equilibrium for some discount factor $\delta>0$. With respect to $\left(\sigma_{H}^{1}, \sigma_{H}^{2}\right)$, firm 1's discounted profit when the starting state is the competitive state $s_{k}$ equals $V(\delta)=\frac{k}{K} h \frac{1}{1-\delta}$. If firm 1 deviates at the first period by setting the low price and continues with $\sigma_{H}^{1}$ afterwards, then firm 1's discounted profit becomes $V^{\prime}(\delta)=\frac{k}{K} \ell+\delta\left[p \frac{k+1}{K} h \frac{1}{1-\delta}+\right.$ $\left.(1-p) \frac{k}{K} h \frac{1}{1-\delta}\right]$, where $p$ denotes the transition probability from state $s_{k}$ to state $s_{k+1}$ when firm 1 sets the low price and firm 2 sets the high price in state $s_{k}$. Since $\left(\sigma_{H}^{1}, \sigma_{H}^{2}\right)$ is an equilibrium for discount factor $\delta$, this deviation by firm 1 cannot be profitable and we must have $V(\delta) \geq V^{\prime}(\delta)$. One can verify that this implies $V\left(\delta^{\prime}\right) \geq V^{\prime}\left(\delta^{\prime}\right)$ for every discount factor 
$\delta^{\prime}$ below $\delta$. This means that this deviation by firm 1 is not profitable even for discount factors below $\delta$. Consequently, based on the one-deviation principle, $\sigma_{H}^{1}$ is a best response to $\sigma_{H}^{2}$, and similarly, $\sigma_{H}^{2}$ is a best response to $\sigma_{H}^{1}$ for discount factors at most $\delta$. Therefore, $\left(\sigma_{H}^{1}, \sigma_{H}^{2}\right)$ constitutes an equilibrium for all discount factors below $\delta$.

3. The existence of $\delta_{3}$. First we prove that $\left(\sigma_{L}^{1}, \sigma_{L}^{2}\right)$ is an equilibrium for sufficiently large discount factors. With respect to $\left(\sigma_{L}^{1}, \sigma_{L}^{2}\right)$ and some discount factor $\delta$, firm 1's discounted profit when the starting state is a competitive state $s_{k}$ equals $\frac{k}{K} \ell_{\frac{1}{1-\delta}}$. If firm 1 deviates at the first period by setting the high price and continues with $\sigma_{L}^{1}$ afterwards, then his discounted profit becomes $\frac{k}{K} h+\delta\left[p \frac{k-1}{K} \ell \frac{1}{1-\delta}+(1-p) \frac{k}{K} \ell \frac{1}{1-\delta}\right]$, where $p$ denotes the transition probability from state $s_{k}$ to state $s_{k-1}$ when firm 1 sets the high price and firm 2 sets the low price in state $s_{k}$. Since the latter amount is smaller for large $\delta$, we may conclude that this deviation by firm 1 is not profitable for large discount factors. Consequently, based on the one-deviation principle, $\sigma_{L}^{1}$ is a best response to $\sigma_{L}^{2}$, and similarly, $\sigma_{L}^{2}$ is a best response to $\sigma_{L}^{1}$ for large discount factors. Therefore, $\left(\sigma_{L}^{1}, \sigma_{L}^{2}\right)$ is an equilibrium for sufficiently large discount factors. One can check, similarly to the part in 2., that if $\left(\sigma_{L}^{1}, \sigma_{L}^{2}\right)$ constitutes an equilibrium for a certain discount factor, then $\left(\sigma_{L}^{1}, \sigma_{L}^{2}\right)$ remains an equilibrium for all higher discount factors. This completes the proof.

In view of the previous proposition, low price strategies constitute a stationary subgameperfect equilibrium for sufficiently large discount factors. However, this equilibrium is not necessarily unique, and there can be other subgame-perfect equilibria even in terms of pure stationary strategies. One can verify that if there are four states $(K=3)$ and the transition probabilities, when the firms choose different prices, are all equal, then $[L H]$ is also a symmetric equilibrium for large discount factors (when $h>3 \ell$ ).

\section{Concluding remarks}

Our model assumes that consumers are either unable or unwilling to switch firms collectively and immediately when faced with a price difference. This implies that firms are unable to immediately increase demand and profit by decreasing their price. Markets in which it is likely to expect that a price decrease by one of the firms does not lead to an immediate capturing of all demand are those where some or all consumers face (high) switching costs. Klemperer (1989) and Beggs and Klemperer (1992) have identified a few industries in which this is likely: the computer industry (once you have familiarized yourself with one producer's system, you might be unwilling to change to another's) and the banking market (it might be quite a hassle to change one's account to another bank). Other markets that are likely to see such consumer behavior are those in which it might be hard for consumers to immediately become aware of price differences. For instance, it might be difficult for consumers to notice 
emerged price differences between the supermarket they usually visit and other alternatives in the neighborhood. Finally, loyalty, consumptive externalities, or the presence of (yearly) contracts are alternative reasons for consumers not to switch en masse and immediately. Our model captures all these situations and therefore the behavioral implications of our results are applicable to these markets.

However, not only the assumptions on the demand side drive our results on pricing behavior, but instead it is the particular time-tradeoff induced by these assumptions that matters. Our results seem to apply to any industry that is characterized with strategic decisions having immediate cost consequences and potential future benefits. For example, the particular timetradeoff manifests in high-tech industries where firms constantly are exposed to decisions to invest in innovative research and development. In our model, the actions in the competitive states are then to be interpreted as high and low R\&D investments and the transition probabilities then represent the likelihood that an investment leads to a successful innovation and an increased attractiveness of the evolved product. As long as the time-tradeoff is preserved our results seem to be robust to an extension to more firms or to a relaxation of the equidistance assumption for the state space. Also the inclusion of absorbing monopolistic states is not critical. Any possibility to increase future profits by pricing aggressively would satisfy the incentives connected to the particular time-tradeoff under investigation. Further evidence that the presence of an absorbing state is not the essential factor driving equilibrium behavior is provided by the last example in Section 4. It is also corroborated by the results from the model with five states, our generalization results and the fact that it is easily possible to find equilibria in which high prices prevail, something that we should not expect if the absorbing monopoly states would play such an influential role. Instead, the essential ingredient of our model is the time-tradeoff that we have introduced. Finally, one yet unnoticed, but remarkable, feature of our model is that no assumptions on product homogeneity or heterogeneity were made; the consequences of price differences are directly translated in the state payoffs and transition probabilities.

An interesting question from a policy maker's perspective is whether market conditions can be regulated in such a way that low prices are implemented. Any policy that facilitates creation of a dominant market position (monopolization), for instance via reduction of switching costs, leads to a decrease in the minimum discount factor for which low prices result. Such a policy may not actually implement a monopolistic market structure, the mere fact that a monopoly position is possible and reachable (for all firms in the market) is what triggers aggressive pricing. From that viewpoint it seems unwise to use government bailouts since this would at the least decrease the perceived probability of bankruptcy and hence monopoly. Also restrictive antitrust policies would lead to a low probability of actually reaching a dominant market position or even monopoly. These policies would then have an upward effect 
on prices in equilibrium. In a similar vein, and related to a finding of Chen and Rosenthal (1996), our results show that it might be unwise to use static measures of market power if the underlying competition is of a dynamic nature. The results of our model with five states show that equilibria are possible in which the market situation fluctuates between all three competitive states, while neither firm eventually attains a monopoly situation. If one would assess the competitive situation at a time when the market would find itself in an asymmetric state, one might conclude that intervention would be necessary, even though the equilibrium strategies would naturally lead the market back to the symmetric state.

\section{References}

[1] Athey S, K Bagwell, and C Sanchirico (2004). Collusion and price rigidity. Review of Economic Studies 71: 317-349.

[2] Beggs A and P Klemperer (1992). Multi-period competition with switching costs. Econometrica 60: 651-666.

[3] Blackwell D (1962). Discrete dynamic programming. Annals of Mathematical Statistics 33: $719-726$.

[4] Burdett K and MG Coles (1997). Steady state price distributions in a noisy search equilibrium. Journal of Economic Theory 72: 1-32.

[5] Cabral L (2009). Dynamic price competition with network effects. Mimeo.

[6] Chen Y and RW Rosenthal (1996). Dynamic duopoly with slowly changing consumer loyalties. International Journal of Industrial Organization 14: 269-296.

[7] Farrell J and P Klemperer (2007). Coordination and lock-in: Competition with switching costs and network effects. In: M Armstrong and R Porter (eds). Handbook of Industrial Organization (Elsevier), Vol. 3, Ch. 31, pp. 1967-2072.

[8] Farrell J and C Shapiro (1988). Dynamic competition with switching costs. Rand Journal of Economics 19: 123-137.

[9] Fink AM (1964). Equilibrium in a stochastic $n$-person game. Journal of Science of the Hiroshima University. Series A-I 28: 89-93.

[10] Fishman A and R Rob (2003). Consumer inertia, firm growth and industry dynamics. Journal of Economic Theory 109: 24-38.

[11] Friedman JW (1971). A non-cooperative equilibrium for supergames. Review of Economic Studies 38: 1-12. 
[12] Herings PJJ and R Peeters (2004). Stationary equilibria in stochastic games: Structure, selection and computation. Journal of Economic Theory 118: 32-60.

[13] Klemperer P (1989). Price wars caused by switching costs. Review of Economic Studies 56: 405-420.

[14] Maskin E and J Tirole (2001). Markov perfect equilibrium, I: Observable actions. Journal of Economic Theory 100: 191-219.

[15] Porter RH and JD Zona (1999). Ohio school milk markets: An analysis of bidding. Rand Journal of Economics 30: 263-288.

[16] Pot E, R Peeters, H Peters, and D Vermeulen (2008). Noncooperative collusion and price wars with individual demand fluctuations. Maastricht University: Meteor Research Memorandum 08/017.

[17] Radner R (2003). Viscous Demand. Journal of Economic Theory 112: 189-231.

[18] Rotemberg JJ and G Saloner (1986). A supergame-theoretic model of price wars during booms. American Economic Review 76: 390-407.

[19] Sobel MJ (1971). Non-cooperative stochastic games. Annals of Mathematical Statistics 42: $1930-1935$.

[20] Takahashi M (1964). Equilibrium points of stochastic, noncooperative $n$-person games. Journal of Science of the Hiroshima University. Series A-I 28: 95-99. 


\section{A Incentives, best responses and equilibria}

In this appendix we illustrate the different incentive and best response structures and resulting equilibrium configurations of our three state model. We fix the following parameters: $h=5$, $\ell=3, p=0.25$ From this we can derive the three threshold values of the discount factor: $\delta_{1}=0.6052, \delta_{2}=0.6154, \delta_{3}=0.7273$. The next seven figures present the seven possible cases that can arise depending on the actual discount factor. The left graph in the figure provides the corresponding incentive structure, where on the vertical axis we plot the normalized present value: $\bar{V}=(1-\delta) V$ (the average expected profit of playing the respective stationary strategies). The middle and right graphs display the resulting best response correspondence and equilibrium configuration respectively.
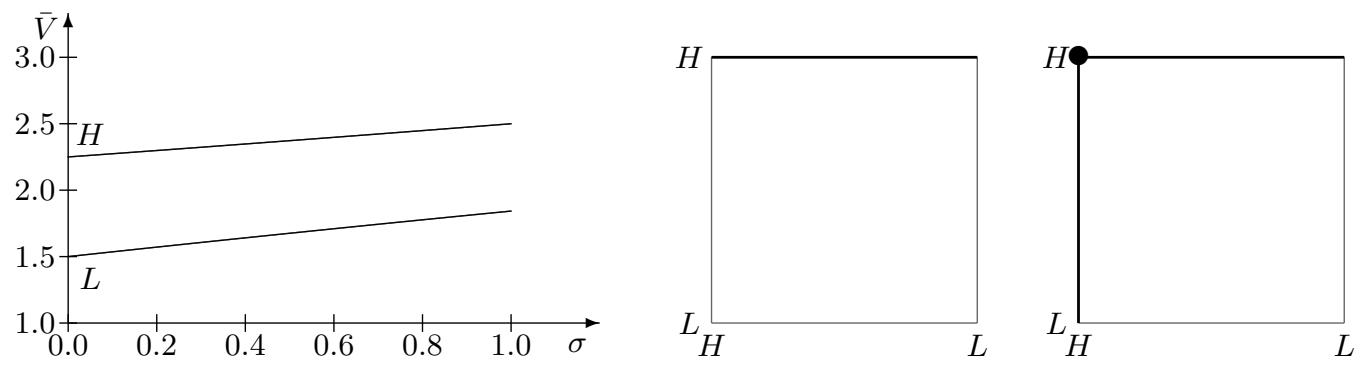

Figure 9: $\delta=0.3026<\delta_{1}$.
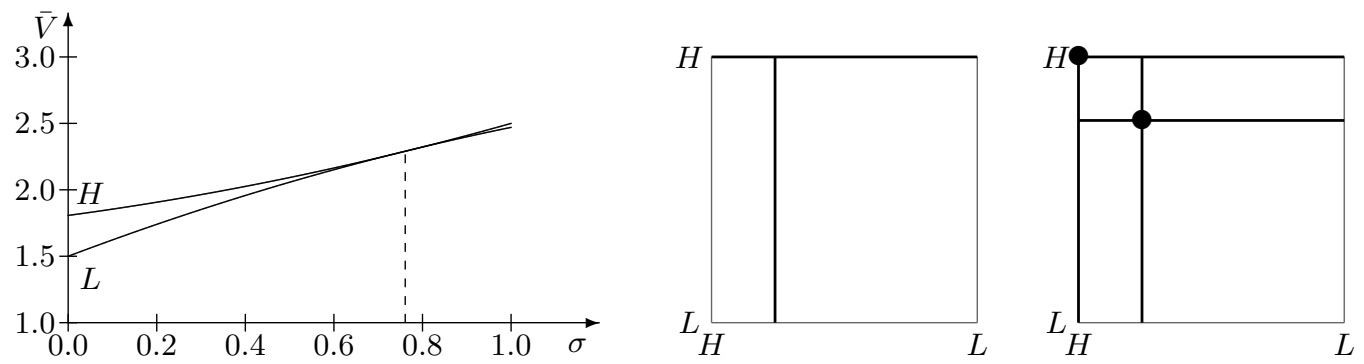

Figure 10: $\delta=0.6052=\delta_{1} ; \sigma_{-}=\sigma_{+}=0.7609$.
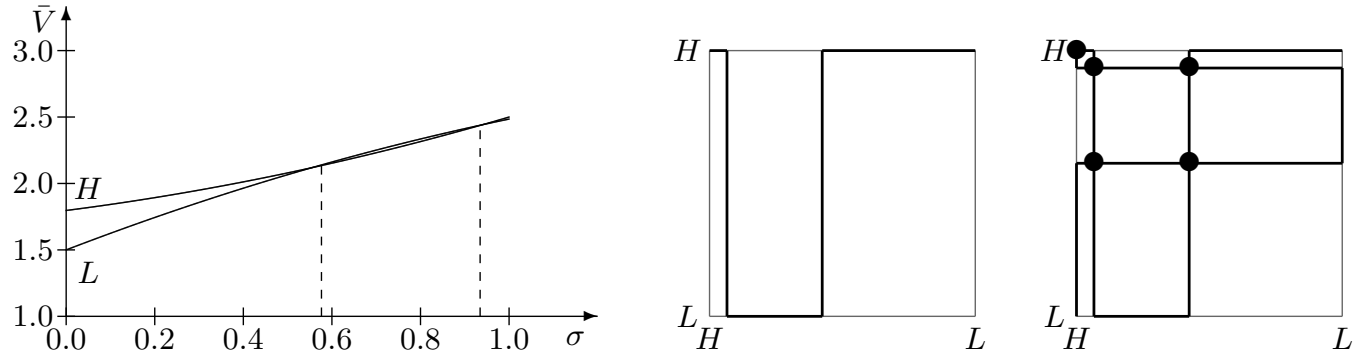

Figure 11: $\delta=0.6103 \in\left(\delta_{1}, \delta_{2}\right) ; \sigma_{-}=0.5763, \sigma_{+}=0.9345$. 

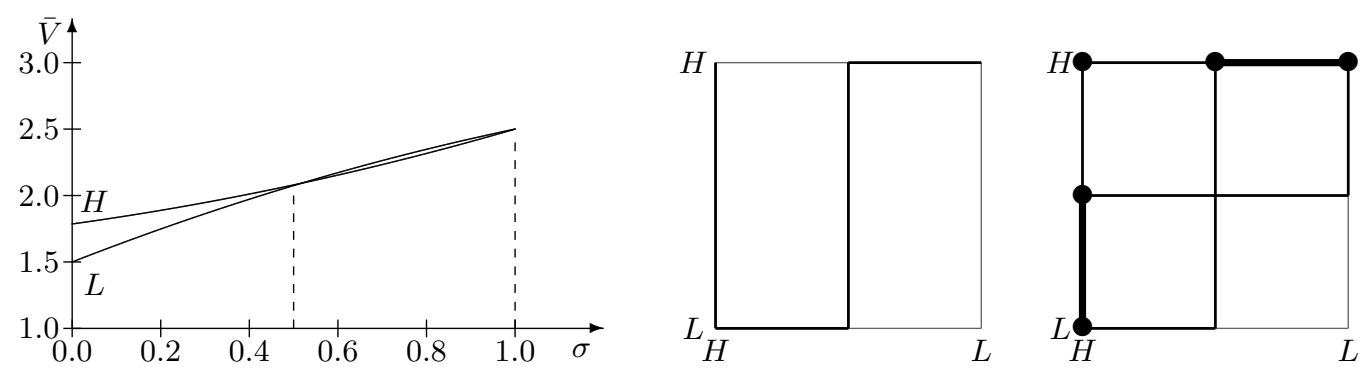

Figure 12: $\delta=0.6154=\delta_{2} ; \sigma_{-}=0.5000, \sigma_{+}=1.0000$.
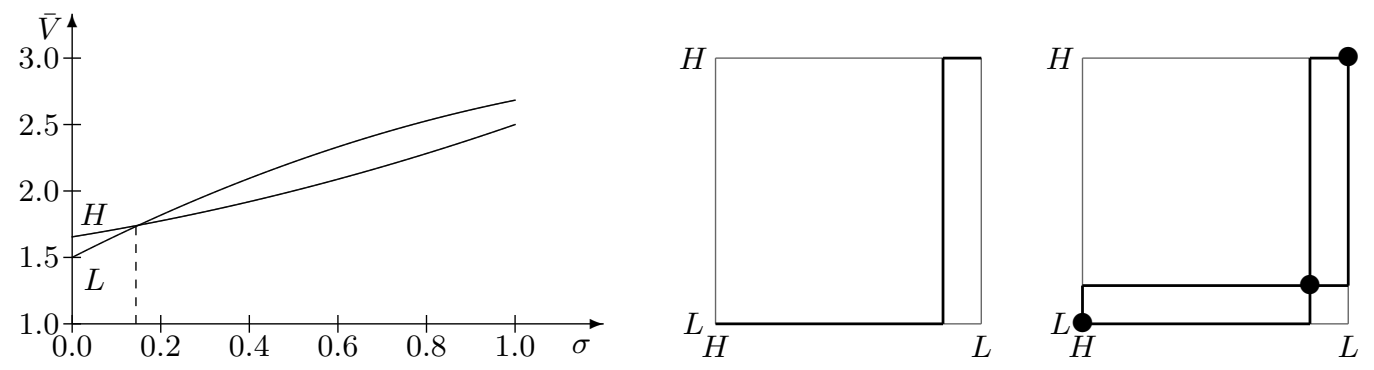

Figure 13: $\delta=0.6713 \in\left(\delta_{2}, \delta_{3}\right) ; \sigma_{-}=0.1439$.
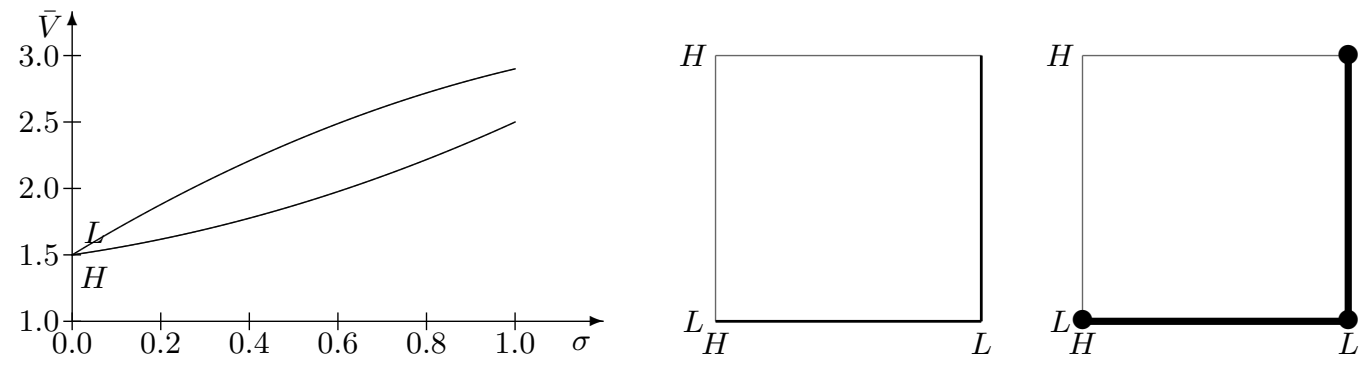

Figure 14: $\delta=0.7273=\delta_{3} ; \sigma_{-}=0.0000$.
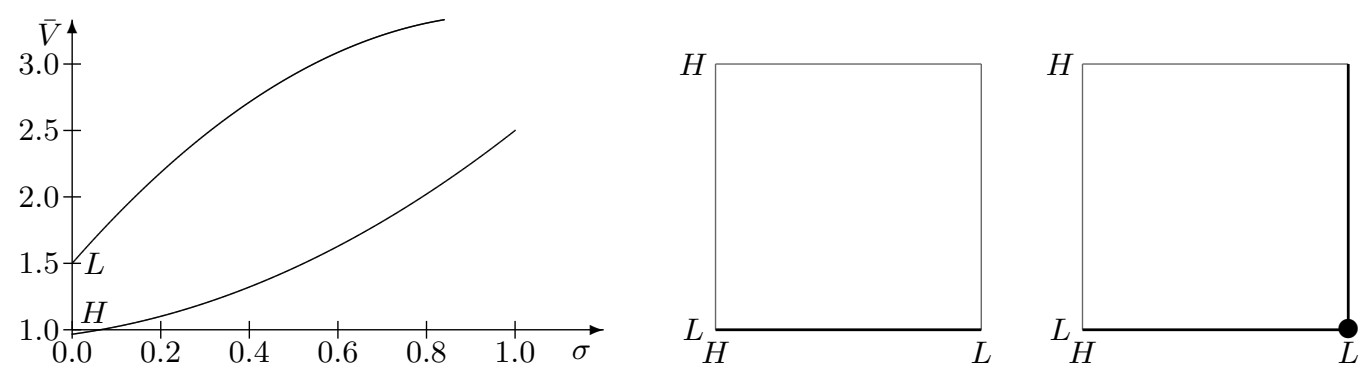

Figure 15: $\delta=0.8636>\delta_{3}$. 